\title{
Welcome New Associate Editors Sandra Wong and Cheng Har Yip to the World Journal of Surgery
}

\author{
Julie Ann Sosa ${ }^{1}$
}

Published online: 20 April 2018

(C) Société Internationale de Chirurgie 2018

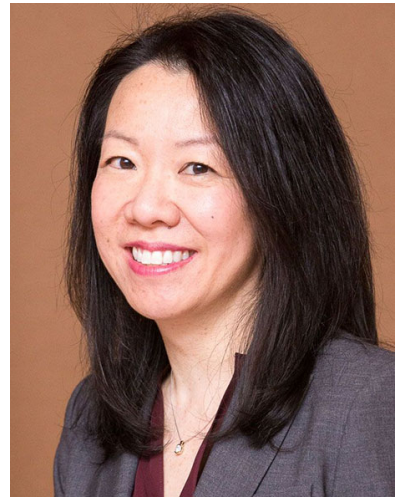

Sandra Wong, MD, MS

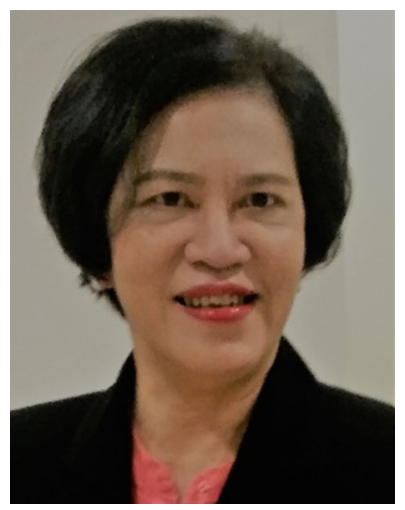

Cheng Har Yip, MBBS

Julie Ann Sosa

julie.sosa@ucsf.edu

1 Department of Surgery, University of California at San Francisco-UCSF, 513 Parnassus Avenue, Suite S320, Box 0104, San Francisco, CA 94143, USA
The World Journal of Surgery is thrilled to announce that Sandra Wong, MD, MS and Cheng Har Yip, MBBS have joined our team of internationally renowned associate editors.

Dr. Wong is the William N. and Bessie Allyn Professor of Surgery at the Geisel School of Medicine at Dartmouth in the United States. She is the Chair of the Department of Surgery and the Senior Vice President of the Surgical Service Line at Dartmouth-Hitchcock Medical Center. She is also Interim Vice President of the Oncology Service Line, Norris Cotton Cancer Center at Dartmouth-Hitchcock, and a member of The Dartmouth Institute for Health Policy and Clinical Practice. Dr. Wong has clinical expertise in soft tissue sarcoma, melanoma and Merkel Cell carcinoma. Her health services research program focuses on quality and costs of cancer care. She is active in the education and mentorship of surgeon-scientists and has been honored with numerous teaching awards. She is currently Treasurer of the Society of University Surgeons and the Society of Surgical Oncology, and she serves on several editorial boards. Dr. Wong graduated from the University of California at Berkeley with an undergraduate degree in Molecular and Cell Biology and minor in Business Administration. She received her medical degree from Northwestern University Medical School in Chicago, Illinois. Dr. Wong completed her General Surgery residency at the University of Louisville and a clinical fellowship in Surgical Oncology at Memorial Sloan-Kettering Cancer Center, where she served as the Chief Administrative Fellow.

Dr. Yip is an academic breast surgeon and consultant at Ramsay Sime Darby Health Care in Malaysia; she is also the lead clinician for the cancer research program at Cancer Research Malaysia, which is a charity based cancer research organization. She is Professor Emeritus at the University of Malaysia, Kuala Lumpur, having retired from 
the active faculty in 2012. Dr. Yip has authored more than 200 peer-reviewed publications. She is a recognized international leader in breast surgery and cancer care and prevention. She served as President of Breast Surgery International (2015-2017), a member organization of the International Surgical Society, as well as the Association of University Surgeons of Asia, the College of Surgeons of Malaysia, and the Asia Pacific Organization for Cancer Prevention. Dr. Yip was Chair of the Development Committee of National Clinical Practice Guidelines for the Management of Breast Cancer in Malaysia in 2010, and she has been appointed as an expert in cancer control by the World Health Organization and the International Atomic Energy Agency. Dr. Yip serves on other editorial boards; she was awarded honorary fellowship from the American College of Surgeons in 2013 and the American Surgical Association in 2017.
Together, Drs. Wong and Yip will provide important guidance around directing publication of high-impact manuscripts in the World Journal of Surgery in their respective fields of expertise in surgical oncology and breast surgery, respectively. This will continue to afford our readership access to the highest quality evidence in order to inform superior surgical care. Welcome to the World Journal of Surgery team, Drs. Wong and Yip!

It is with mixed emotions that we say goodbye to our outgoing associate editors, Drs. Walter Marti of Basel, Switzerland and Kerstin Sandelin of Stockholm, Sweden. Together, they have provided more than two decades of service to the World Journal of Surgery, offering impeccable judgment around triaging manuscripts in their respective areas of specialty to assure that the best science consistently rose to the top. We offer our deepest thanks to both Drs. Marti and Sandelin; they will be sorely missed. 